\title{
The performance of water cooled photovoltaic panel, under concentrating system
}

\author{
Ahmed A. Aqeel Al-shurman ${ }^{\text {a, b }}$, Mohamed R. Gomaa ${ }^{\text {b,c }}$ \\ ${ }^{a}$ Jordan phosphate mines company (JPMC), Amman, Jordan \\ ${ }^{\mathrm{b}}$ Mechanical Department, Faculty of Engineering, Mutah University, Al-Karak, Jordan \\ ${ }^{\mathrm{c}}$ Mechanical Department, Benha Faculty of Engineering, Benha University, Benha, Egypt \\ Correspondence Author: Ahmed A. Aqeel (Al-Shurman), Jordan phosphate mines company (JPMC), Amman, Jordan. \\ E-mail: eng_shurman@yahoo.com
}

Received date: 20 May 2019, Accepted date: 20 July 2019, Online date: 28 July 2019

Copyright: (C) 2019 Ahmed A. Aqeel (Al-Shurman) et al., This is an open-access article distributed under the terms of the Creative Commons Attribution License, which permits unrestricted use, distribution, and reproduction in any medium, provided the original author and source are credited

\begin{abstract}
This work presents the performance study of the concentrating photovoltaic/thermal (CPV/T) collector and its efficiency for production thermal and electric energy under different operating conditions. The study covers detailed description of flat-plate and (CPV/T) systems, using water as a working fluid, numerical model analysis, and qualitative evaluation of thermal and electrical output.

The aim of this study is to achieve higher efficiency of the photovoltaic (PV) system while reducing the cost of generating power. Concentrating photovoltaic (CPV) cells with low cost reflectors have been used to enhance the efficiency of the PV system and simultaneously reduce the cost of electricity generation. For this purpose, Linear Fresnel flat mirror (LFFM) integrated with PV system is use for low-concentration PV cells (LCPV). To achieve the maximum benefit, water as a coolant material is used to study the ability of actively cool PV cells, since the electrical power of the CPV system is significantly affected by the temperature of the PV cells.

This system is characterized by the traditional PV systems by producing more electrical energy due to the concentrating the solar radiation as well as cooling the PV modules and at the same time produces thermal energy which can be used in domestic applications.

During the analysis of the results of the proposed system, it was found that the maximum electrical and thermal energy obtained was $170 \mathrm{~W}$ and $580 \mathrm{~W}$, respectively at solar concentration ratio 3 and the flow rate of the cooling water $1 \mathrm{~L} / \mathrm{min}$. This amount of electrical and thermal energy is approximately three times of the amount produced when using PV module without concentrating system and coolant flow rate $0.1 \mathrm{~L} / \mathrm{min}$, which is estimated at $61 \mathrm{~W}$ and $155 \mathrm{~W}$, respectively.
\end{abstract}

Keywords: Photovoltaic, cooling system, efficiency, concentrating system

\section{INTRODUCTION}

Nowadays, 80 percent of the world energy is produced from fossil fuels (Efstartios Channiotakis, 2001). The exhaust products of using these resources affect the environment, mainly through global warming and acid rain.

Currently, oil provides more than $35 \%$ of the global primary energy, coal, and natural gas add $23 \%$ and $21 \%$ respectively (Goldemberg, 2000; Johansson and Goldemberg, 2002).

The fossil fuels distribution around the world is uneven, with more than half of them in the Middle East. This leads to an unbalanced economy around the world that affects the whole political geography. The burning of fossil fuel produces atmospheric emission of $\mathrm{CO}_{2}$ (carbon dioxide), where its concentration will cause an average temperature rise of 3-5 ${ }^{\circ} \mathrm{C}$ (Efstartios Channiotakis, 2001).

Taking into account above, as well as the fact that oil is running out quickly, alternatives should be adopted. Renewable energy is one of the promising options for the above problems. PV (Photovoltaic) panels, in particular, can provide a good source of producing clean electricity. The efficiency range of conversion solar radiation is about 5-20\%, depend on the type of the cell (JohnTwidell and Tony Weir, 2006).

Most commercial PV cells are made from silicone and come in two general types, mono-crystalline, and multi-crystalline (Paul A. lynn, 2010). This type of PV cells is the most efficient, with approximately $15 \%$ efficiency. The amount of sun energy converted to electrical power depends on the intensity of solar radiation fall in PV cells (He W et al., 2006). 
PV cells absorb up to $80 \%$ of incident solar radiation but depending on the efficiency of the PV cell technology used, an only small part of the absorbed incident energy is converted into electricity (He W et al., 2006). The remainder energy that was absorbed by the PV cell is dissipated as heat, and the PV cell can reach temperature $40^{\circ} \mathrm{C}$ above the ambient. The overheating reduces the efficiency of the panels dramatically. The efficiency of the PV cell affected by its temperature, when the temperature of the PV module is increased, the efficiency drops. Depending on the PV type, the approximate descent of efficiency around $0.5 \% / /{ }^{\circ} \mathrm{C}$ from the cell operating temperature.

Many ways of cooling the PV module will present and discussed. A steady-state of PV/T (Photovoltaic/Thermal) air heating collector and water-cooled PV/T are kinds of them (Yogesh S Bijjaryi et al., 2016).

The optimum cooling solution is dependent on several factors such as PV technology, type of concentration generates, and weather conditions at which the system is installed. The annual performance indicated that the delivered energy from the PV modules increases 5\% during dry and worm seasons (Saad Odeh and Masad Behnia, 2011).

To promote the production of electricity from PV units, which is the main purpose of its construction, we must reduce the operating temperature to improve the efficiency (temperature rising leading to a decrease transform solar energy into electricity). Reducing temperature can be done by using a cooling medium such as water and air. Using water in a hybrid cooling system is more efficient than using air because the thermal prosperities of water are better than air (He W et al., 2006).

(M.Y. Othman et al., 2016) Provide a merge of both air and water medium with the conventional PV/T collector, and the obtained results are shown in Table 1. The main components fabricated in the system are two transparent PV modules connected in parallel to generate electrical power, double pass air flat plat collector, copper water tube and reservoir for hot water producing. Experimental values were measured on PV temperature, the air temperature on both channels, and water temperature.

Table 1: PV/T system cooling by water and air

\begin{tabular}{|c|c|c|c|c|}
\hline $\begin{array}{c}\text { Solar radiation } \\
I,\left(\mathrm{~W} / \mathrm{m}^{2}\right)\end{array}$ & $\begin{array}{c}\text { Maximum power } \\
P_{\text {max }},(\mathrm{W})\end{array}$ & $\begin{array}{c}\text { Total useful energy } \\
Q_{\text {combi }}(\mathrm{J})\end{array}$ & $\begin{array}{c}\text { Total Thermal efficiency } \\
\eta_{\text {th }},(\%)\end{array}$ & $\begin{array}{c}\text { Electric efficiency } \\
\eta_{\mathrm{el}},(\%)\end{array}$ \\
\hline 350 & 48.0 & 743.8 & 73.79 & 13.71 \\
\hline 500 & 88.0 & 1022.0 & 70.97 & 17.60 \\
\hline 650 & 118.8 & 1717.3 & 70.25 & 18.30 \\
\hline 800 & 159.6 & 1926.6 & 70.09 & 19.95 \\
\hline
\end{tabular}

(Ahmad Fudholi et al., 2014) Determined the electrical and thermal performance of PV cells cooled by water under solar radiation ranging from $500 \mathrm{~W} / \mathrm{m}^{2}$ to $800 \mathrm{~W} / \mathrm{m}^{2}$. For each solar radiation level, a flow rate of $0.01 \mathrm{~kg} / \mathrm{s}$ to $1.041 \mathrm{~kg} / \mathrm{s}$ was introduced. The electrical, thermal and total efficiency of the PV/T collectors was examined. The result showed that the spiral flow absorption was highest at $800 \mathrm{~W} / \mathrm{m}^{2}$ solar intensity and $0.41 \mathrm{~kg} / \mathrm{s}$ water flow rate, with an electrical efficiency of $13.8 \%$, the thermal efficiency of $54.6 \%$ and overall efficiency of $68.4 \%$.

The mixed solar PV system and solar heat PV/T is an alternative solar solution, which offers a distinct advantage of providing one-unit form thermal output, as well as an electric output with improved efficiency compared to PV stand-alone units if properly designed (María Herrando and Christos N. Markides, 2016).

Other cooling mediums can be used to extract the heat from the PV such as oils and Nano-fluids, which can be used in different methods.

Attention has been focused on the use of practical, durable, and inexpensive reflectors to increase the electricity produced from PV cells to become price competitive in the market.

An important goal in this work is also to highlight the effect of temperature on PV cells and to develop an LCPV/T model to simulate the effect of cooling on similar systems performance to increase the overall efficiency of solar systems.

\section{THEORETICAL MODEL}

Based on all the above studies and research to obtain a home-based PV system, easy to install and maintain, operate more efficiently than the efficiency of normal systems and using relatively cheap and available materials. It was proposed to study the overall efficiency of the system shown in Fig. 1, which consists of two mono-crystalline PV module mounted vertically, connected from the back and subjected to solar concentration by flat mirrors, which are cooled by water pass through copper pipes attached to the lower surfaces of the two modules together.

The system will be analysed in two parts, the first part highlights on the solar concentration system and the equipment used for this purpose which is LFRFM (linear Fresnel Reflector Flat Mirrors), and then calculate the reflective solar radiation of these mirrors.

The second part will focus on the receiver, its parts and the calculation of solar radiation reach to it from the sun and concentrates. 

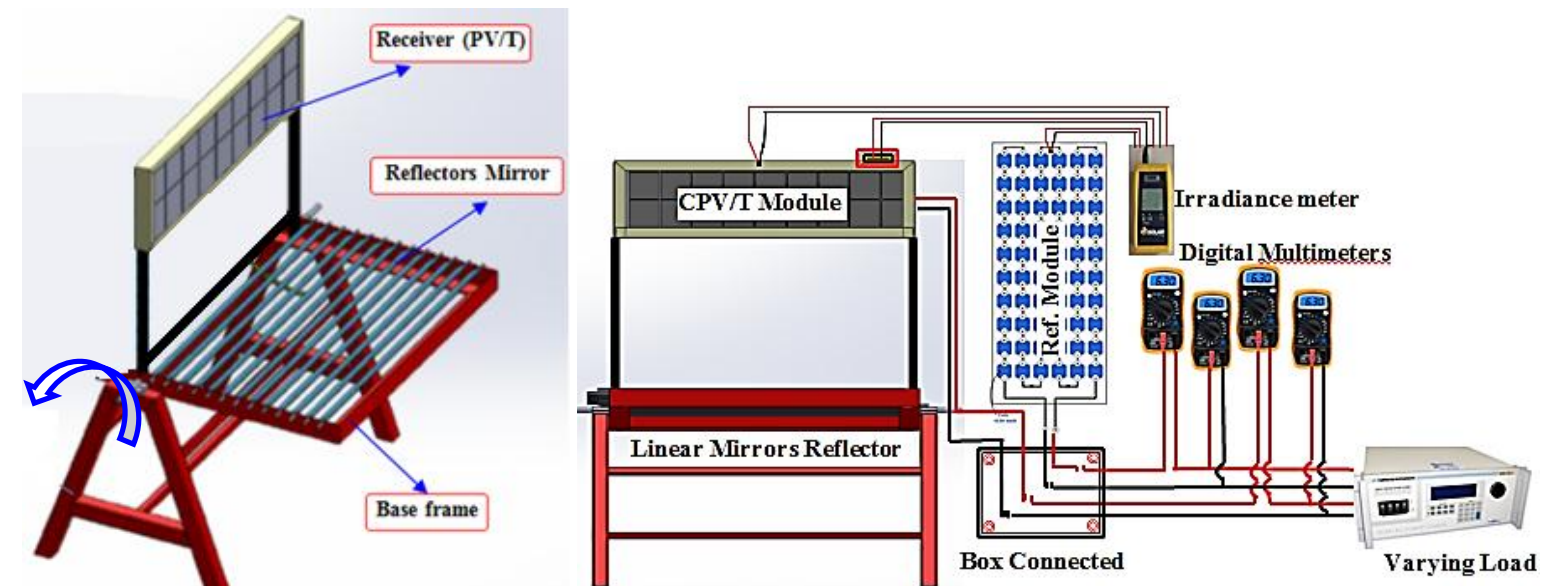

Fig. 1: Concentrating (a)tovoltaic/Thermal system,(a) LFRFM concentrating system,(b) sy:(b)। assembly

\section{Solar Concentrating System (SCS)}

Solar energy is the most widespread and available and is a clean source of energy, and since the solar radiation intensity is only 500-1000W/m $/ \mathrm{m}^{2}$ (P.K. Sen et al., 2013) the solar concentrating system (SCS) is needed to make greater use of solar radiation. In this research, Linear Fresnel Reflectors Flat Mirrors (LFRFM) was chosen to be the mechanism of the concentrating solar radiation, as shown in Fig. 1a.

The schematic diagram system is shown in Fig. 1bcan be used as a domestic appliance to produce electric and thermal energy needed. The system is established to be carried and easy to store and transmitted, with dimensions of $0.75 * 2$ meter.

LFRFM concentrator system (Fig. 2a and 2b) equation designs are showed and presented as in equations 1 to 4 .

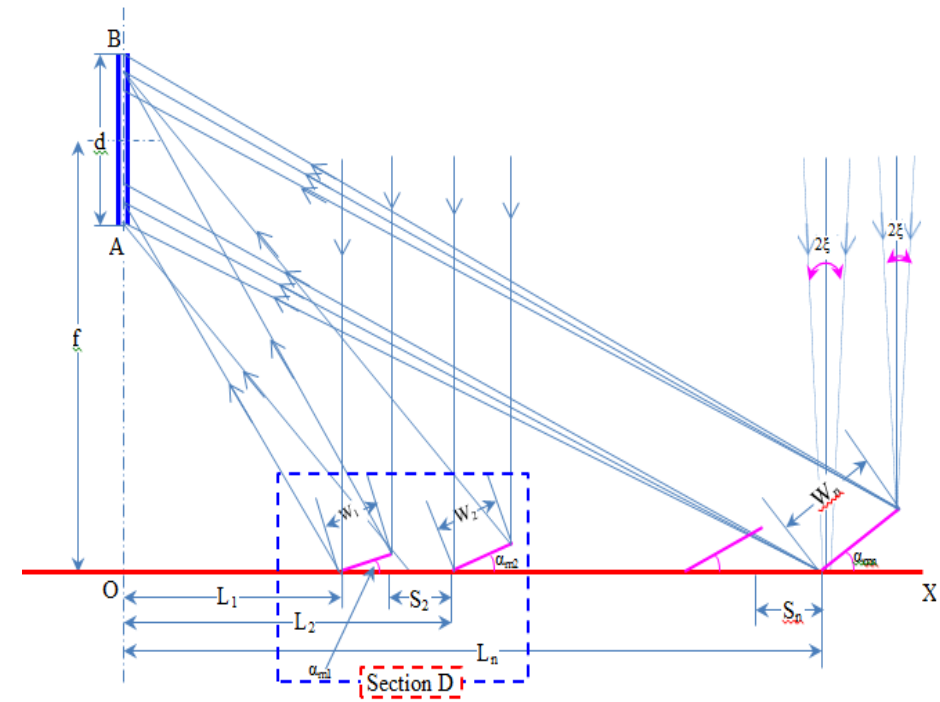

(a)

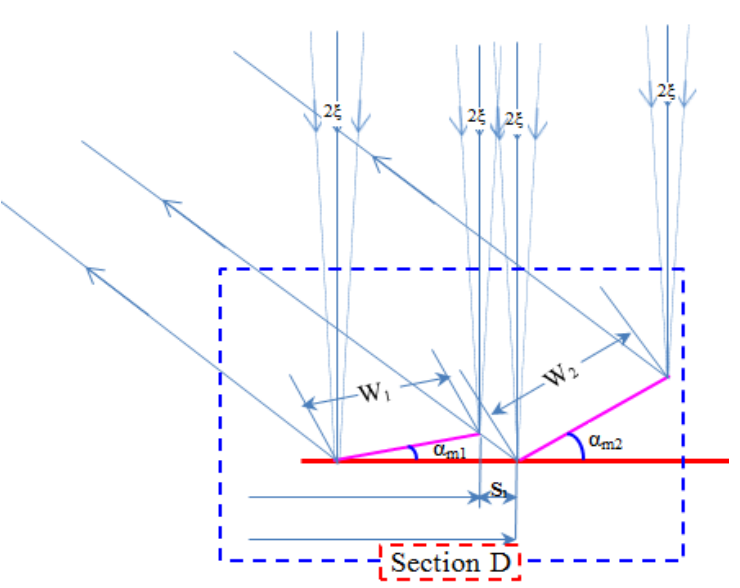

(b)

Fig. 2: (a) Linear Fresnel concentrator system, (b) enlarge mirrors radiation (section D)

The mirrors inclination angle $\alpha_{m, n}$ is calculated from the general form as;

$\alpha_{m, n}=\frac{1}{2}\left[\tan ^{-1}\left(\frac{L_{n}}{f-\frac{d}{2}}\right)-\xi_{0}\right]$

The width of the mirrors $\left(W_{n}\right)$ calculated from Eq. 2;

$W_{n}=\frac{\left[d \sin \left(2 \alpha_{m, n}-\xi_{0}\right) \sin \left(2 \alpha_{m, n}+\xi_{0}\right)\right]-L_{n} \sin 2 \xi_{0}}{\sin \left(2 \alpha_{m, n}+\xi_{0}\right) \cos \left(\alpha_{m, n}-\xi_{0}\right)}$

The reflected radiation $I_{\text {refl }}$ reach the receiver is given by the Eq. 3 .

$I_{\text {refl }}=I_{T} \cdot C_{R} \cdot \rho_{m}$

Where $C_{R}$ is the concentration ratio and calculated as in Eq. 4.

$C_{R}=\frac{A_{m}}{A_{r}}$

where $A_{r}$ is the receiver area in $\mathrm{m}^{2}$. 


\section{Incident solar radiation to the mirrors}

The first step in calculating the useful energy from PV/T is to calculate the amount of solar radiation reaching the surface of the earth, whether direct, diffuse or ground and then exploited it to obtain the largest possible amount of thermal and electrical energy. The Eqs. 5, 6, 7, and 8give the direct beam radiation incident on mirrors reflector and incident angles of radiation fall on a tilted surface (Kelly, 2010). Fig. 3 shows the angle of solar radiation falling on the surface, and the important angles used to calculate the amount of solar radiation of various kinds.

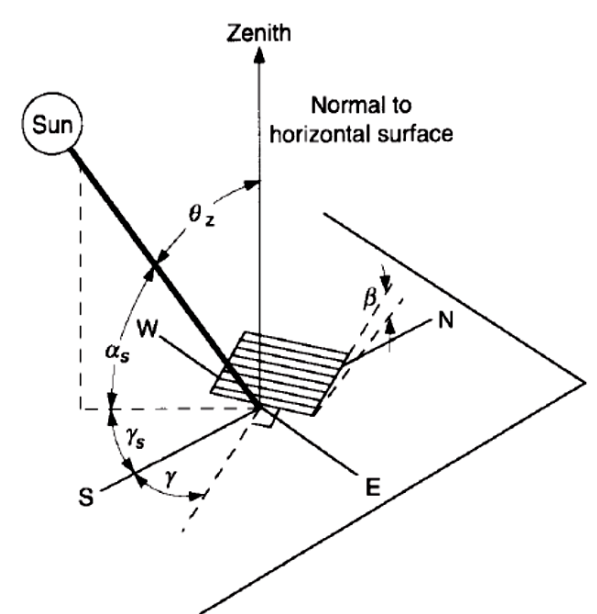

(a)

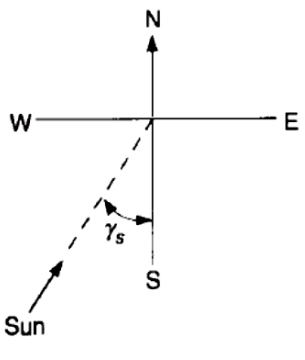

(b)

Fig. 3: (a) The angle of solar radiation falling on the surface, (b) plan view showing azimuth angle

The direct radiation incident on the surface is calculated as;

$I_{b \beta}=I_{b h}\left(\cos \alpha_{s} \cos \alpha \cos \beta^{\prime}+\sin \alpha_{s} \sin \beta^{\prime}\right)$

Where $I_{\mathrm{b} \beta}$ is the direct radiation incident on the surface $\left(\mathrm{W} / \mathrm{m}^{2}\right), I_{\mathrm{bh}}$ is the direct beam radiation on a horizontal plane $\left(\mathrm{W} / \mathrm{m}^{2}\right)$, $\alpha_{s}$ is the altitude of sun from horizontal, $\alpha$ is the angle between surface normal and solar beam azimuth which is equal to the angle between the solar beam and the longitude meridian $\left(\gamma_{s}\right)$ minus the angle between the normal to the surface and the local longitude meridian $(\gamma)$ and $\beta^{\prime}$ is the surface angle from vertical. The equation 7 and 8 used to calculate $\alpha_{s}$ and $\gamma_{s}$ (M.Y. Othman et al., 2016):

$\alpha_{s}=\sin ^{-1}(\cos \phi \cos \omega \cos \delta+\sin \phi \sin \delta)$

where $\emptyset$ is the Longitude, $\omega$ is the solar hour, and $\delta$ is the angle between the sun direction and the equatorial plane

$\gamma_{s}=\cos ^{-1}\left(\frac{\sin \phi \cos \omega \cos \delta-\cos \phi \sin \delta}{\cos \alpha_{S}}\right)$

$\delta=\delta_{o} \cdot \sin \left(\frac{360(284+n)}{365}\right)$

where $n$ is the day of the year and $\delta_{o}=23.45^{\circ}$

\section{Solar radiation incident to the receiver sandwich}

Ones the irradiance is calculated, electrical and thermal yields can be determined. The total solar radiation absorbed by the receiver of CPV/T system $I_{T}^{\prime}$ is equal to the sum of direct radiation on the PV surface $I_{b}^{\prime}$, the sky-diffuse radiation $I_{d}^{\prime}$, the ground reflected radiation $I_{g r}^{\prime}$ and the radiation reflected from the mirrors $I_{\text {refl }}^{\prime}$ (Shafiqur Rehman et al., 2015).

The total incident solar radiation intensity reached to the receiver is calculated from Eq.9;

$I^{\prime}{ }_{T}=I^{\prime}{ }_{b}+I^{\prime}{ }_{d}+I^{\prime}{ }_{g r}+I^{\prime}{ }_{\text {refl }}$

where $I_{b}^{\prime}$ is the beam absorbed radiation by the receiver and is obtained by:

$\mathrm{I}^{\prime}{ }_{b}=\left(\mathrm{I}_{\mathrm{T}} \cos (\alpha \mathrm{s}+\beta 1)\right)(\tau \alpha)_{b}$

where $I_{T}$ is the total incident solar radiation intensity $\left(\mathrm{W} / \mathrm{m}^{2}\right), \beta_{I}$ is the base frame angle from horizontal and $(\tau \alpha)_{b}$ is effective transmittance-absorptance product of cover for beam radiation (-).

The diffuse absorbed radiation by the receiver is calculated as;

$\mathrm{I}^{\prime}{ }_{d}=\mathrm{I}_{\mathrm{d}}\left(\frac{1+\cos (270+\beta 1)}{2}\right)(\tau \alpha)_{d}$

The ground radiation absorbed by the receiver presented by:

$I^{\prime}{ }_{g r}=\rho_{g r} I_{o}\left(\frac{1-\cos (270+\beta 1)}{2}\right)(\tau \alpha)_{g r}$ 
The reflect radiation absorbed by the receiver

$I^{\prime}{ }_{\text {refl }}=\rho_{m} I_{T} \sin (x) \sin (\alpha s-\alpha m)(\tau \alpha)_{b}$

where $\rho_{\mathrm{m}}$ is the mirror reflectivity, $x$ is the reflected radiation angle from the receiver in the left side and $\alpha_{m}$ is the mirror angle from horizontal.

\section{Thermal model}

The modeling analyses are based on some assumptions to obtain the energy balance of different components of PV/T water collector as; (1) The system is in steady-state condition, (2) The temperature variation along the thickness is negligible, (3) The heat capacities of solar cell material, Tedlar, and insulation have been neglected, and (4) The water flow through water pipe is uniform.

Figure 4(a) and $(b)$ illustrates receiver components and the length of the absorber element $(d x)$ connected with the coolant water pipe, respectively. Figure 5 shows the equivalent thermal resistance circuit applied to the system. These resistances are calculated and used to obtain the thermal parameters and to find the PV/T water collector efficiency.

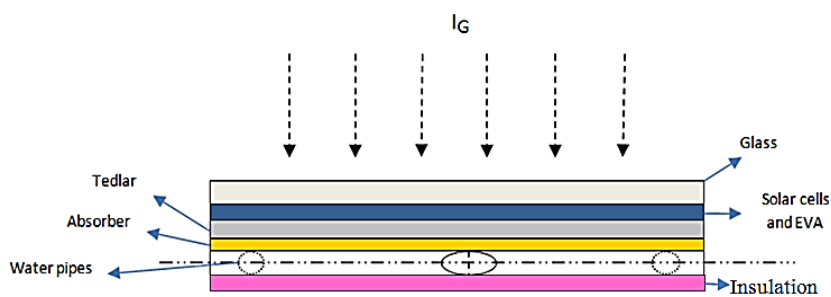

(a)

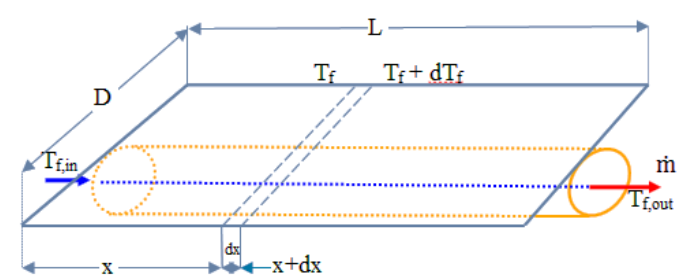

(b)

Fig. 4: (a) Receiver components $(b)$ The length of the absorber element $(d x)$

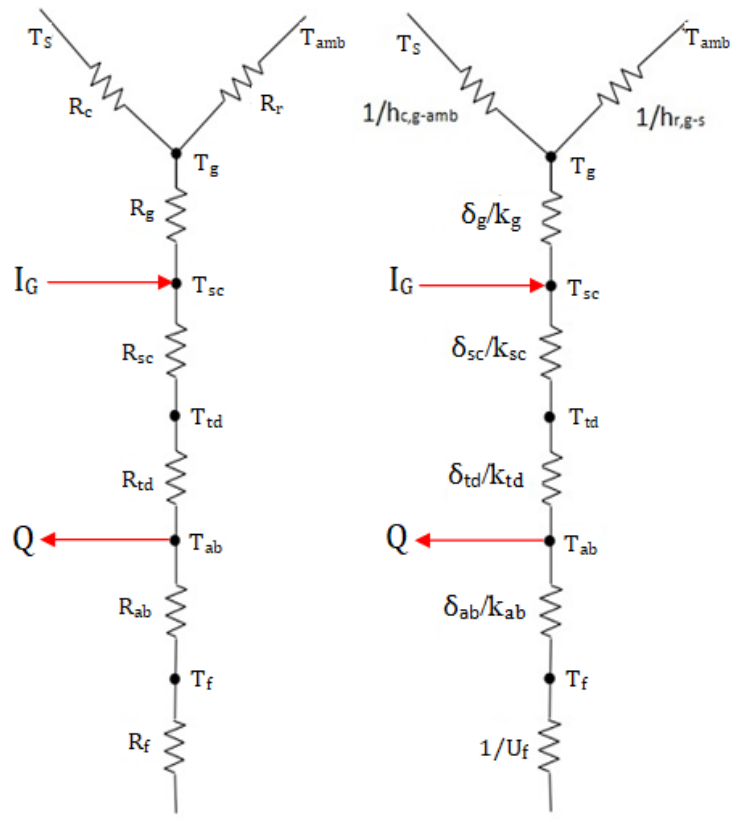

(a) The equivalent thermal resistance of one side of the receiver

(b) Value of thermal resistance of one side of the receiver

Fig. 5: The equivalent network thermal resistance circuit for the receiver

Refer to Fig. 5 the energy balance equations for each component of the PV/T module is presented. Considering the glassTedlar component, so;

$\left.\tau_{g}\left[\alpha_{s c} \beta_{s c} I_{G}+\alpha_{t d}\left(1-\beta_{s c}\right) I_{G}\right] \cdot D \cdot d x=\left[U_{s c-a m b}\right)\left(T_{s c}-T_{a m b}\right)+U_{s c-t d}\left(T_{s c}-T_{t d}\right)\right] \cdot D \cdot d x+\tau_{g} \beta_{s c} \eta_{e l} I_{G} \cdot D \cdot d x$

where $\beta_{s c}$ is the packing factor (the fraction of Tedlar plate area covered by the solar cells), $I_{\mathrm{G}}$ is the solar intensified radiation on the receiver $\left(\mathrm{W} / \mathrm{m}^{2}\right), \tau_{\mathrm{g}}$ is the glass transmissivity $(-), \alpha_{s c}$ is the solar cell absorptivity $(-), \alpha_{\mathrm{td}}$ is the tedlar absorptivity $(-)$, and $D$ is the absorber width $(\mathrm{m})$.

Finally, the calculated solar cell temperature as a function of back surface (Absorber) temperature is deduced as:

$T_{s c=}\left[(\tau \alpha)_{e f f} I_{G}+U_{s c-a m b} T_{a m b}+U_{s c-t d} T_{t d}\right] /\left(U_{s c-t d}+U_{s c-a m b}\right)$ 
Citation: Ahmed A. Aqeel (Al-shurman), et al., The performance of Water Cooled Photovoltaic Panel, under Concentrating System. Australian Journal of Basic and Applied Sciences, 13(7): 12-22. DOI: 10.22587/ajbas.2019.13.7.3

The outlet cooling water temperature and amount of useful heat transferred to the heat removal agent, water, finding both from Eqs.16 and 17 (M. Arif Hasan and K. Sumathy, 2010);

$T_{f, \text { out }}=\left(T_{a m b}+\frac{2 h_{p 1} h_{p 2} \cdot\left[(\tau \alpha)_{e f f} \mathrm{I}_{G}\right]}{U_{L}}\right)\left(1-\exp \left(-\frac{\mathrm{F}^{\prime} U_{L} \cdot(\mathrm{D} \cdot \mathrm{L})}{\dot{\mathrm{m}} \cdot \mathrm{C}_{\mathrm{p}}}\right)\right)+T_{f, \text { in }} \cdot \exp \left(-\frac{\mathrm{F}^{\prime} U_{L} \cdot(\mathrm{D} \cdot \mathrm{L})}{\dot{\mathrm{m}} \cdot \mathrm{C}_{\mathrm{p}}}\right)$

where $T_{f \text {, out }}$ is the fluid outlet temperature $(\mathrm{K}), T_{f, \text { in }}$ is the fluid inlet temperature $(\mathrm{K}), L$ is the absorber length (m), $\dot{m}$ is the mass flow rate of water $(\mathrm{kg} / \mathrm{s})$, and $C_{P}$ is the specific heat capacity of water $(\mathrm{kJ} / \mathrm{kg} . \mathrm{K})$.

$Q_{u}=F_{R} \cdot 2(\mathrm{~L} \cdot \mathrm{D})\left[2 h_{p 1} h_{p 2} \cdot\left[(\tau \alpha)_{e f f} \mathrm{I}_{G}\right]-U_{L}\left(T_{f, i n}-T_{a m b}\right)\right]$

where $F_{\mathrm{R}}$ is the heat removal efficiency factor and obtained from;

$F_{R}=\frac{\dot{\mathrm{m}} C_{p}}{U_{L} \cdot 2(\mathrm{~L} \cdot \mathrm{D})}\left[1-\exp \left(-\frac{F^{\prime} U_{L} \cdot(\mathrm{L} \cdot \mathrm{D})}{\dot{\mathrm{m}} C_{p}}\right)\right]$

and the thermal efficiency is found as:

$\eta_{t h}=\frac{Q_{u}}{2 \cdot\left[I_{G} \cdot A\right]}=\frac{Q_{u}}{2 \cdot\left[I_{G}(L \cdot D)\right]}=\frac{F_{R}}{I_{G}}\left[2 h_{p 1} h_{p 2} \cdot\left[(\tau \alpha)_{e f f} \mathrm{I}_{G}\right]-U_{L}\left(T_{f, i n}-T_{a m b}\right)\right]=F_{R}\left[2 h_{p 1} h_{p 2}(\tau \alpha)_{e f f}-\left(U_{L} / I_{G}\right)\left(T_{f, i n}-T_{a m b}\right)\right]$

Finally, the useful water heat transfer resulted from Eq. 20 presented as;

$Q_{u}=F_{R} \cdot 2(\mathrm{~L} \cdot \mathrm{D})\left[2 h_{p 1} h_{p 2} \cdot\left[(\tau \alpha)_{e f f} \mathrm{I}_{G}\right]-U_{L}\left(T_{f, i n}-T_{a m b}\right)\right]$

and the thermal efficiency is found as:

$\eta_{t h}=\frac{Q_{u}}{2 \cdot\left[I_{G} \cdot A\right]}=\frac{Q_{u}}{2 \cdot\left[I_{G}(L \cdot D)\right]}=\frac{F_{R}}{I_{G}}\left[2 h_{p 1} h_{p 2} \cdot\left[(\tau \alpha)_{e f f} \mathrm{I}_{G}\right]-U_{L}\left(T_{f, i n}-T_{a m b}\right)\right]=F_{R}\left[2 h_{p 1} h_{p 2}(\tau \alpha)_{e f f}-\left(U_{L} / I_{G}\right)\left(T_{f, i n}-T_{a m b}\right)\right]$

The electrical efficiency of a PV module, $\eta_{\mathrm{el}}$ has been calculated from the following equation (A. A. Ghoneim and A. M. Mohammedein, 2016);

$\eta_{e l}=\eta_{e l, r e f}\left[1-\mu_{s c}\left(T_{s c}-T_{r e f}\right)\right]$

where $\eta_{e l, \text { ref }}$ is a reference efficiency of the solar cell at solar irradiance $1000 \mathrm{~W} / \mathrm{m}^{2}, \mu_{s c}$ is the percentage of electrical loss per temperature degree $\left(\mu_{s c}=0.0045\right)$ and temperature $T_{r e f}=25 \mathrm{C}^{\circ}$.

The combined PV/T efficiency of the system is the sum of photovoltaic and thermal efficiencies of the system as:

$\eta_{\text {overall }}=\eta_{\text {th }}+\eta_{\text {el }}$

where $\eta_{\text {overall }}$ is the overall efficiency of the combined PV/T system.

\section{RESULTS AND DISCUSSION}

The performance of the PV system was studied when changing the amount of solar radiation from $200-1000 \mathrm{~W} / \mathrm{m}^{2}$ and changing the amount of cooling water flow from $0.1-1 \mathrm{~L} / \mathrm{min}$ at different solar concentration ratio. In this study, the average wind speed is $3 \mathrm{~m} / \mathrm{s}$, and the temperature of the cooling water inside is $293 \mathrm{~K}$.

The electrical energy of this system under the influence of solar concentration from 1-3 is shown in Fig. 6, so that the amount of energy produced from the system increases with increasing solar concentration and the amount of radiation falling. Where the maximum electric power produced increased from $65 \mathrm{~W}$ at a solar concentration ratio 1 to $170 \mathrm{~W}$ at the solar concentration ratio 3 , it also shows that the highest amount of energy produced at the highest flow rate of $1.5 \mathrm{~L} / \mathrm{min}$ at all stages of change concentration ratio.

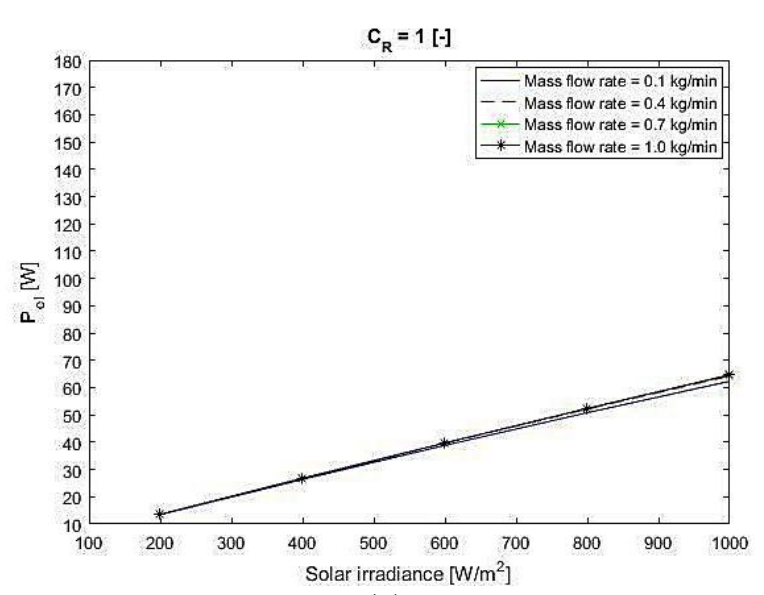

(a)

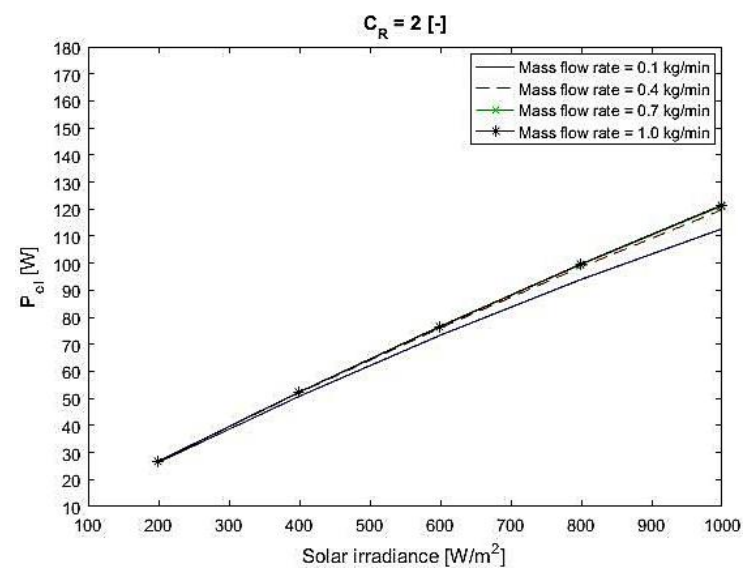

(b) 


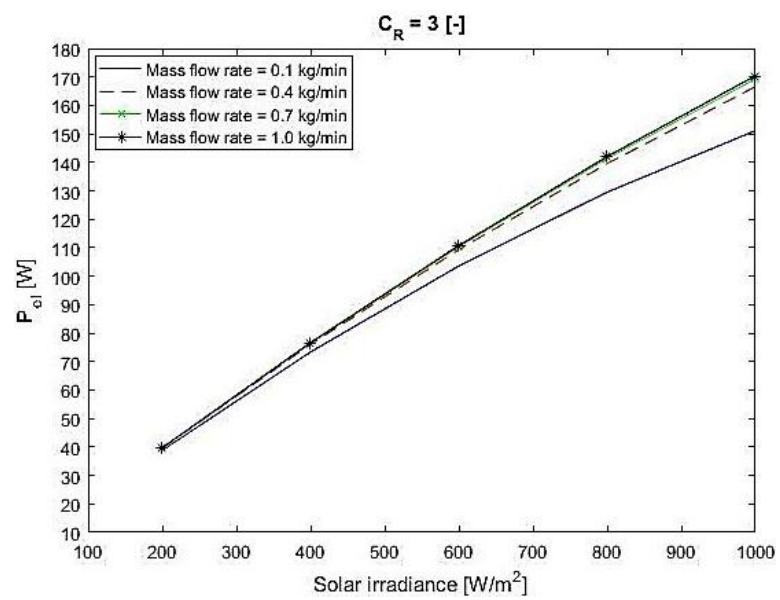

(c)

Fig. 6: Electric power versus solar radiation for different $C R$

Figure 7 and Figure 8 show the change in the temperature of the solar cells and the temperature of the heat absorber, respectively, with the change in solar radiation and the solar concentration ratio. The change in the temperature of the solar cells is linked to the change in the temperature of the heat absorber. They increase together with an increased amount of solar radiation and solar concentration ratio and decrease together with their decrease.

Cooling, as presented reduces the temperature of the solar cells and the absorber. It is observed that the lower the flow, the higher the temperature of the solar cells. The temperature of the solar cells may reach under the solar concentration ratio 3 and the flow rate $0.1 \mathrm{~L} / \mathrm{min}$ at solar irradiance $1000 \mathrm{~W} / \mathrm{m}^{2}$ to $355 \mathrm{~K}$ and the absorbent temperature to $330 \mathrm{~K}$ in the same operational conditions.

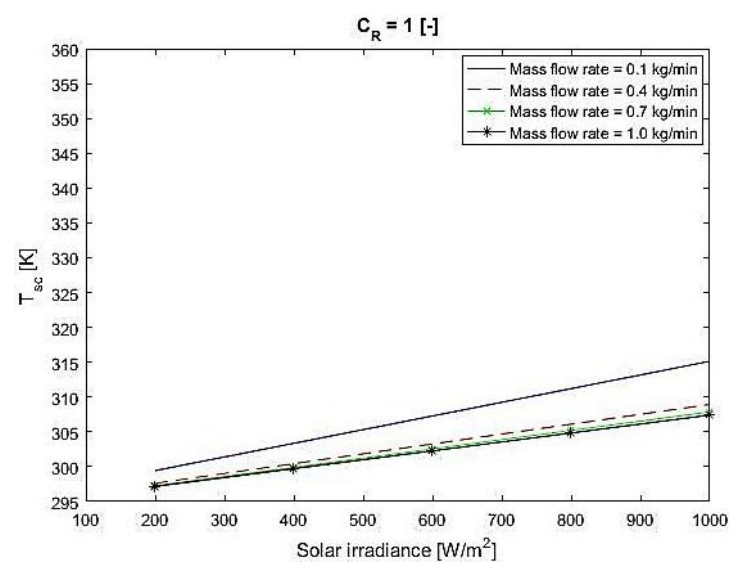

(a)

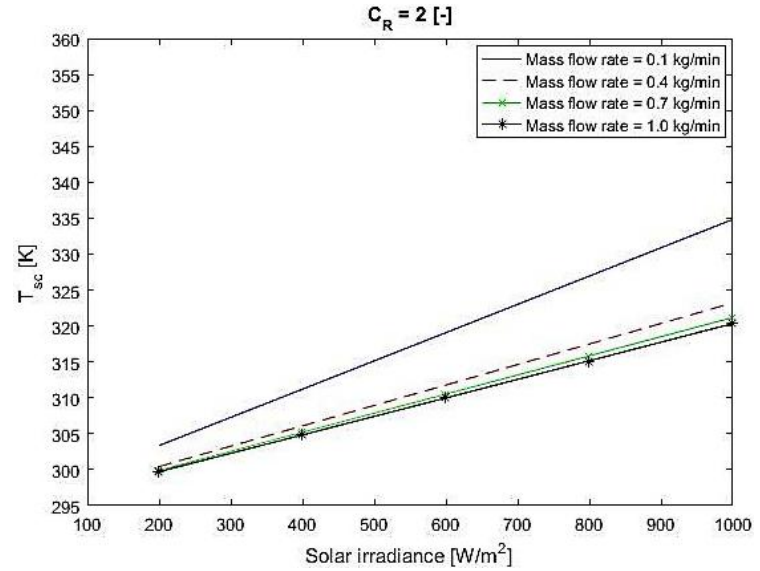

(b)

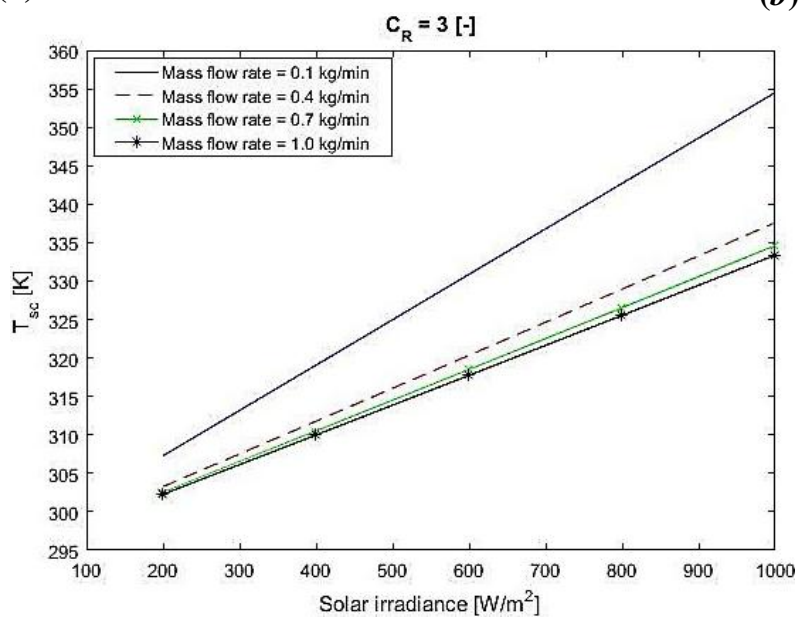

(c)

Fig. 7: Solar cell temperature versus solar radiation for different CR 
Citation: Ahmed A. Aqeel (Al-shurman), et al., The performance of Water Cooled Photovoltaic Panel, under Concentrating System. Australian Journal of Basic and Applied Sciences, 13(7): 12-22. DOI: 10.22587/ajbas.2019.13.7.3

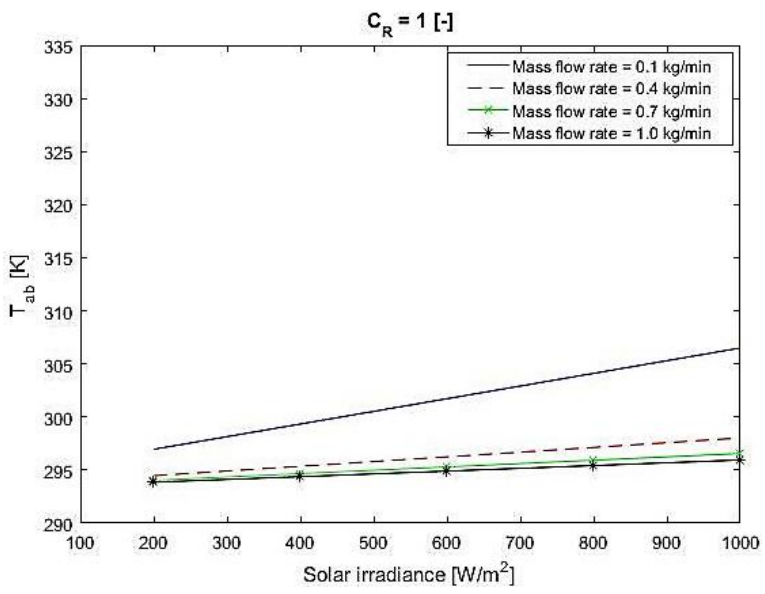

(a)

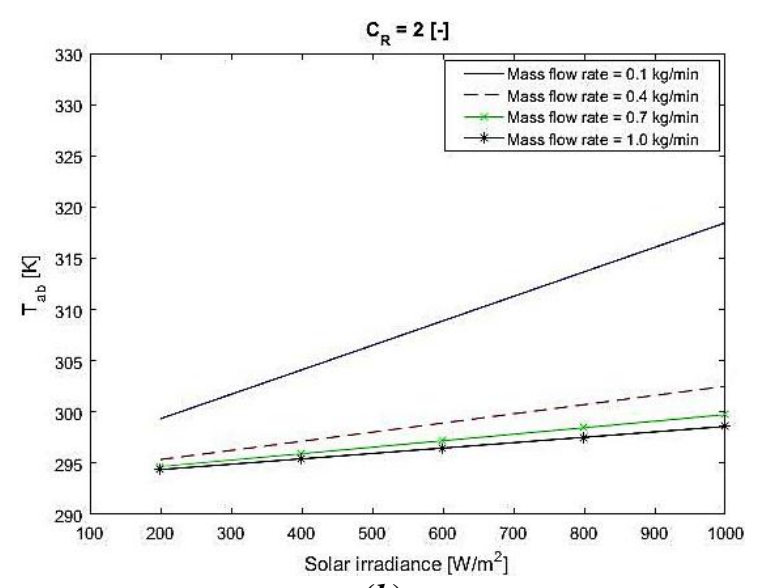

(b)

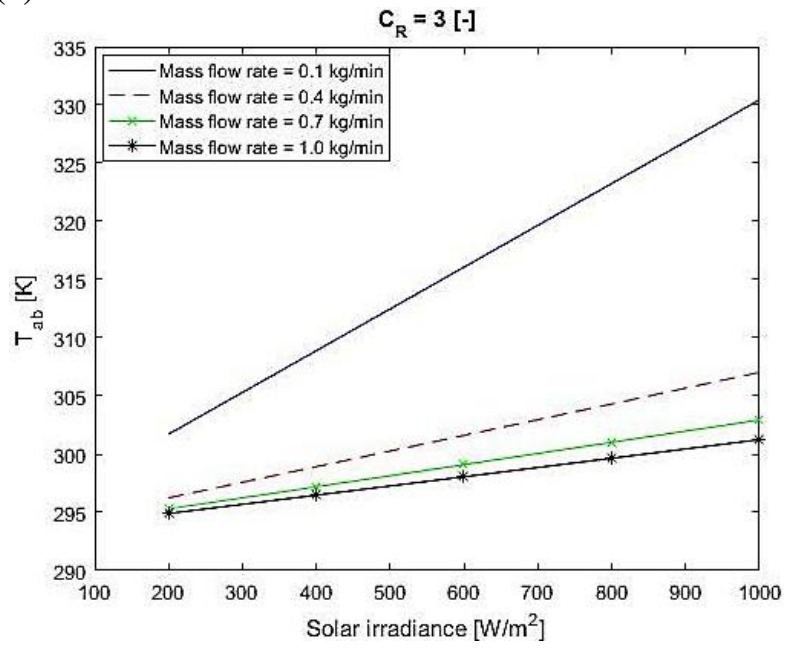

(c)

Fig. 8: Absorber plate temperature versus solar radiation for different CR

The electrical efficiency of the system under the same operating conditions is discussed in Fig. 9, which shows that solar radiation negatively affects electrical ability. Since the solar concentration rate is a reflection of the amount of solar radiation falling on the surface, increasing the solar concentration rate also adversely affects the electrical efficiency of the solar system.

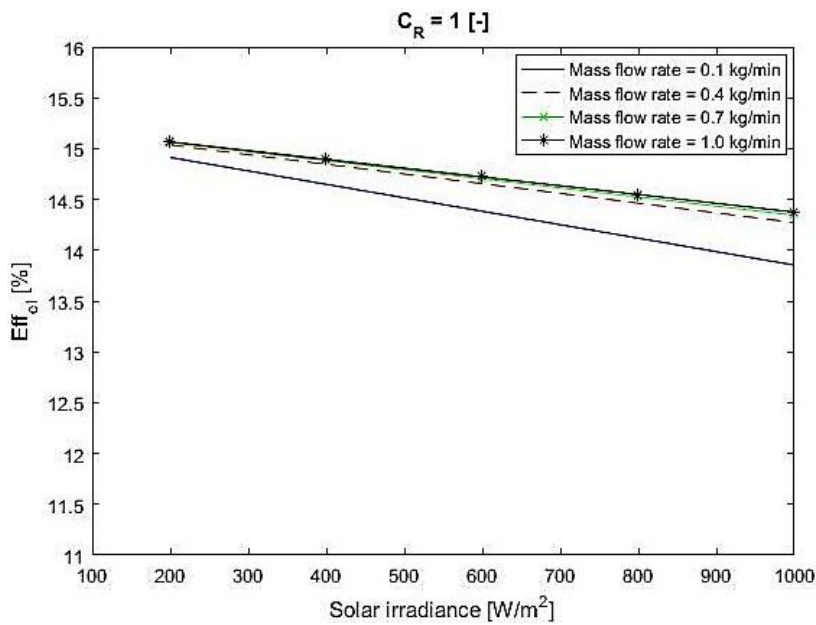

(a)

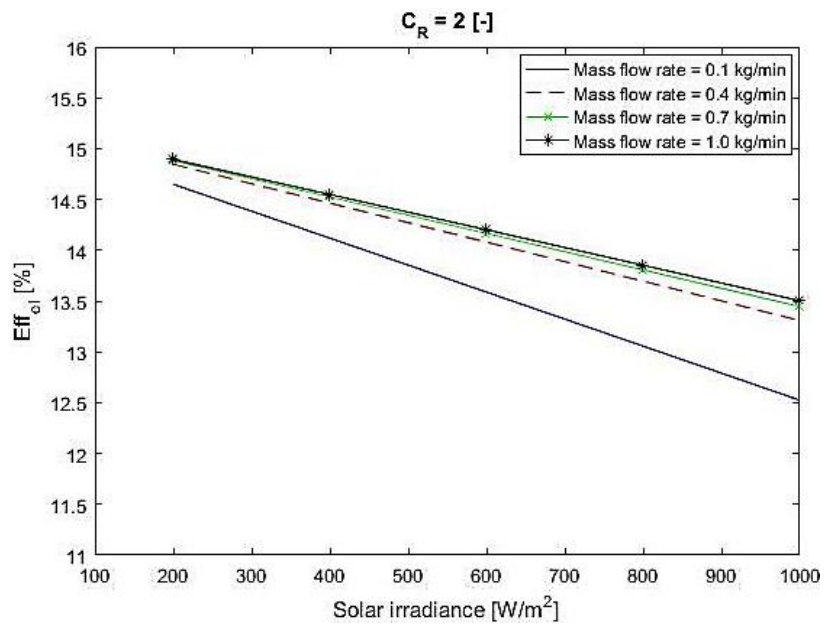

(b) 


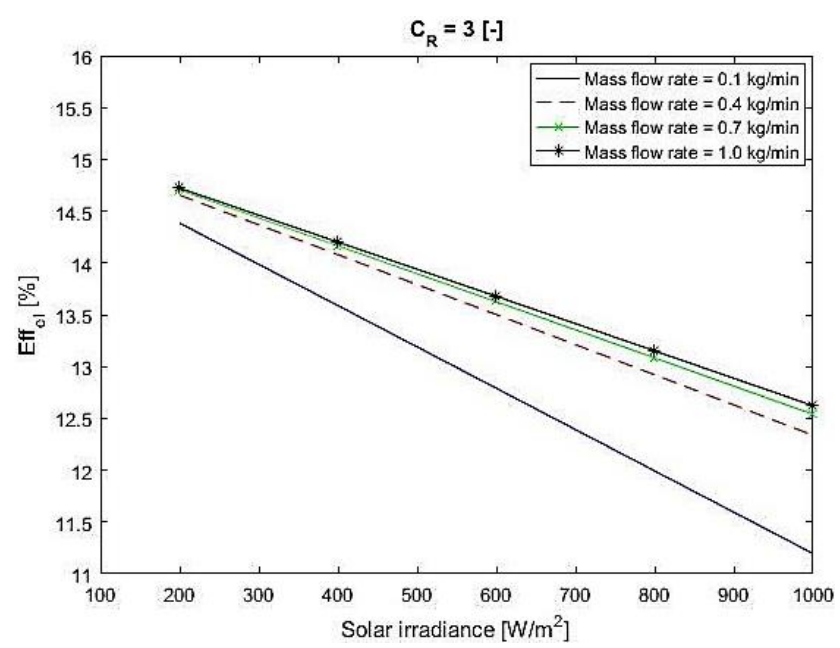

(c)

Fig. 9: Solar panel efficiency versus solar radiation for different CR

It is also evident in Fig.9 that the electrical efficiency may decrease from 13.9\% at the concentration ratio 1 and the amount of flow $0.1 \mathrm{~L} / \mathrm{min}$ to $11.2 \%$ at the same solar radiation $1000 \mathrm{~W} / \mathrm{m}^{2}$ and concentration ratio 3 . The large decrease in electrical efficiency can be reduced by increasing the flow of cooling water so that the electrical efficiency increases asan example to $13.1 \%$ if we increase the amount of flow to 1 at the concentration ratio 3 and solar radiation $1000 \mathrm{~W} / \mathrm{m}^{2}$.

The same impression observed in the electrical efficiency of the system applies to the thermal efficiency as in Figure 10, so that increasing concentration ratio and solar radiation reduces thermal efficiency, while increasing the flow of cooling water reduces the efficiency deficit. Based on Figure 10, the highest thermal efficiency is $68 \%$ at 1 concentration ratio and $200 \mathrm{~W} / \mathrm{m}^{2}$ solar radiation with a flow rate of $1 \mathrm{~L} / \mathrm{min}$ and a lower thermal efficiency is $32 \%$ at 3 concentration ratio and $1000 \mathrm{~W} / \mathrm{m}^{2}$ solar radiation with a flow rate of $0.1 \mathrm{~L} / \mathrm{min}$.

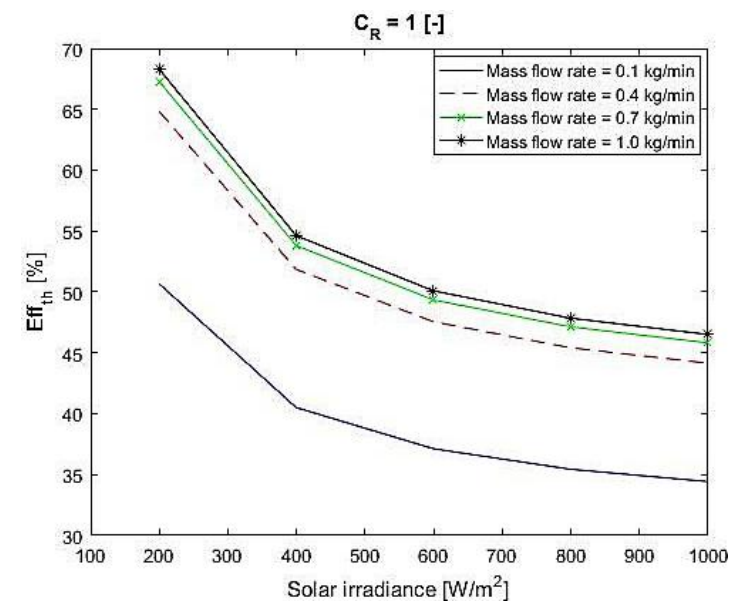

(a)

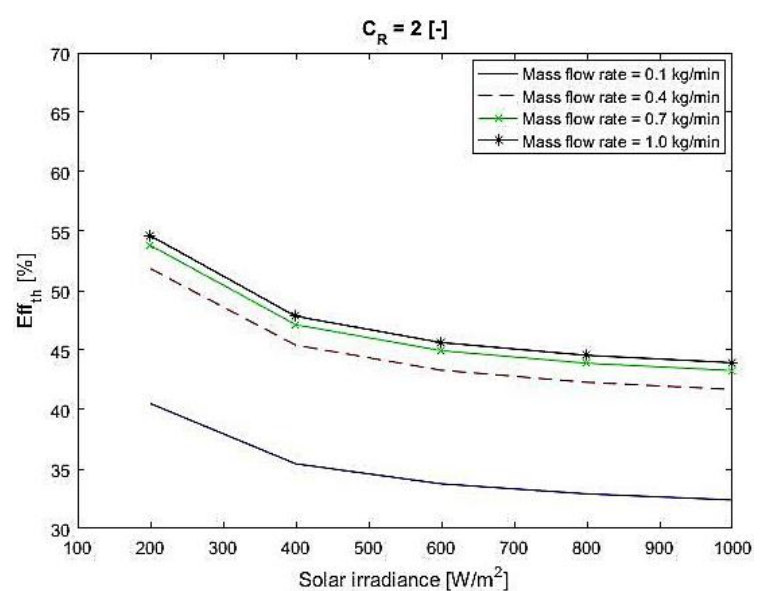

(b)

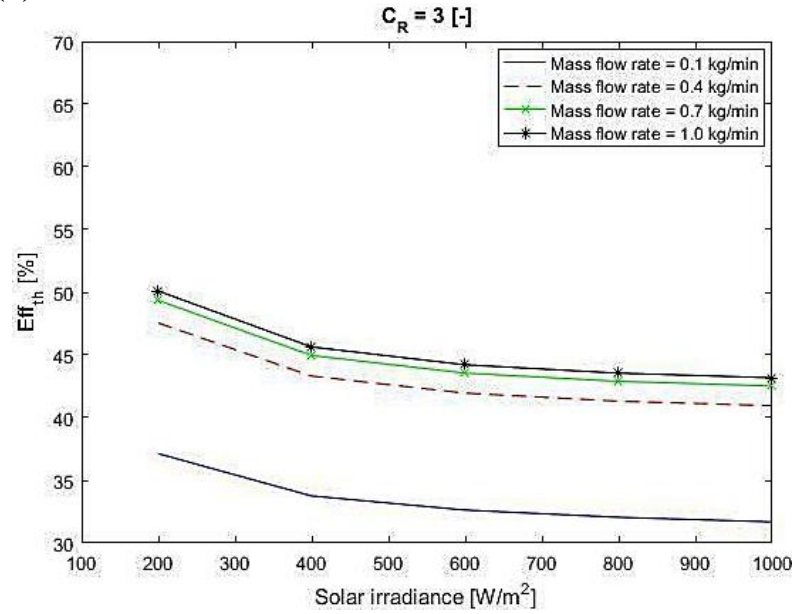

(c)

Fig. 10: Thermal efficiency versus solar radiation for different CR 
Figure 11 shows the relationship of thermal energy with solar radiation under the influence of a variable solar concentration ratio. The results show a significant increase in thermal energy, when the solar concentration ratio and solar radiation increase, as well as the increased flow rate of cooling water, increases the thermal energy produced.

The highest thermal energy quantity was recorded is $580 \mathrm{~W}$ at solar concentration 3 , solar radiation $1000 \mathrm{~W} / \mathrm{m}^{2}$ and flow quantity $1 \mathrm{~L} / \mathrm{min}$, while thermal energy at solar level 2 was $400 \mathrm{~W}$ and at solar concentration 1 was $210 \mathrm{~W}$ under the same operating conditions.

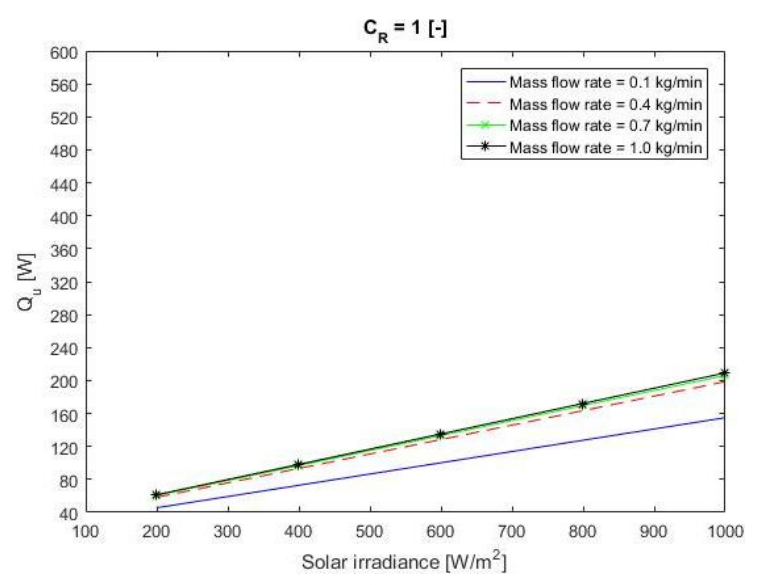

(a)

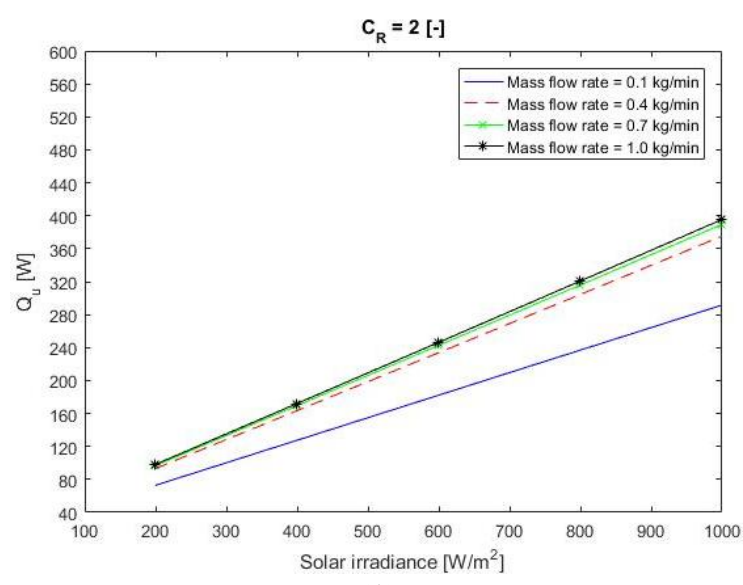

(b)

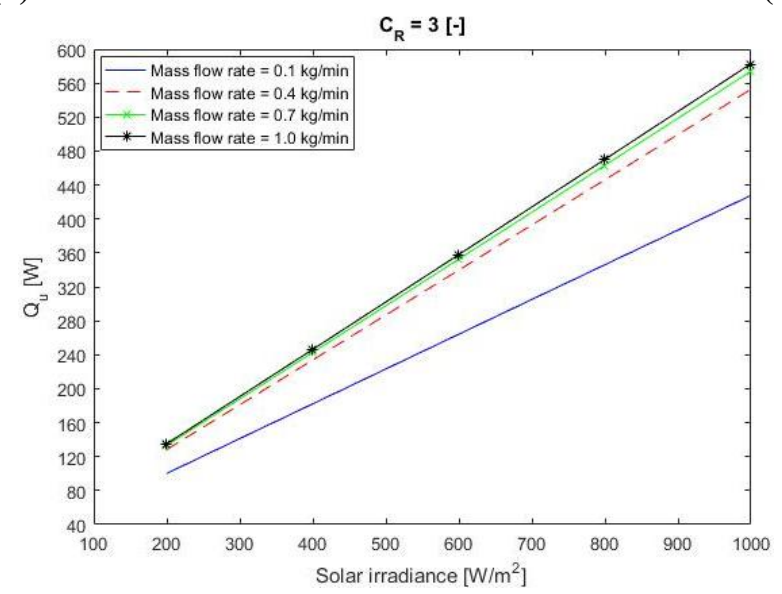

(c)

Fig.11: Thermal energy versus solar radiation for different CR

After studying a set of variables on the performance of the proposed solar system, it is shown that electrical and thermal efficiency decreases with increasing solar concentration and solar radiation, increasing the amount of flow of cooling water, while electrical and thermal energy, temperature of solar cells and temperature of heat absorber increases with increasing solar radiation and decreases by increasing the flow of cooling water.

\section{CONCLUSION}

In this work, a theoretical analysis of a CPV/T was presented, in this model the performance of photovoltaic cells that use the high solar concentration and are cooled by a high flow of cooling water is much higher than their performance when using a solar with a small concentration and a small amount of flow under the same operation condition.

During the system analysis of the results, it was found that the maximum electrical and thermal energy obtained was $170 \mathrm{~W}$ and $580 \mathrm{~W}$, respectively, at solar concentration ratio 3 and the flow rate of the cooling water $1 \mathrm{~L} / \mathrm{min}$. This amount of electrical and thermal energy is approximately three times the amount produced when using a standard module without concentration and coolant flow rate $0.1 \mathrm{~L} / \mathrm{min}$, which is estimated at $61 \mathrm{~W}$ and $155 \mathrm{~W}$, respectively.

Increasing the solar radiation and solar concentration, which is a reflection of the increase of solar radiation, increases the electrical and thermal efficiency of solar cells, but this increase in solar radiation increases the temperature of solar cells and the temperature of the heat absorber, which negatively affects the electrical and thermal efficiency.

Increasing the amount of cooling water through the collector improves heat recovery from the PV module and thus increases electrical and thermal efficiency. Cooling is also necessary for PV modules that use solar concentration, to prevent the temperature of the solar cells reaching high temperatures that reduce their efficiency and increase the possibility of cell damage.

One of the most important benefits of solar systems that use solar concentrators is that they give a much higher energy amount than systems that do not use concentrators and operating under the same operating conditions, by using cheap solar concentrators instead of high price PV modules with the possibility of using thermal energy produced in domestic applications. 


\section{REFERENCES}

Efstartios Channiotakis. Modelling and analysis of water cooled photovoltaic. Unpublished MSc theses. Department of mechanical engineering, University of Strathclyde. 2001.

Goldemberg, J., ed. World Energy Assessment. Energy and challenge sustainability. United Nations Development programme, 2000.

Johansson, T.B. and J. Goldemberg, eds. Energy for sustainable: apolicy agenda, United Nations Development programme, 2002

JohnTwidell and Tony Weir.Renewable energy resources. USA \& Canada: Tayler\&francis, 2006.

Paul A. lynn. Electricity from sunlight. London: John Wiley \& sons, 2010.

Yogesh S Bijjaryi, Kale S.S and Shaikh K.A.Cooling technique for photovoltaic module for improving its conversion efficiency. International Journal of mechanical engineering and technology, 04 (07), (2016), 22-28.

SaadOdeh, MasadBehnia. Improving photovoltaic module efficiency using water cooling.Heat transfer engineering30: 2009. (2011), 499-505. http://dx.doi.org/10.1080/01457630802529214

He W., Chow T.T., Ji J., Lu J., Pei, G. L. Hybrid photovoltaic andthermal solar-collector designed for natural circulation of water. Chan, Applied Energy 83 (2006) 199-210.

M.Y. Othman et al. Performance analysis of PV/T Combi with water and air heating system: An experimental study. Renewable Energy 86 (2016) 716-722.http://dx.doi.org/10.1016/j.renene.2015.08.061

Ahmad Fudholi et al. Performance analysis of photovoltaic thermal (PVT) water collectors.Energy Conversion and Management 78 (2014) 641-651.http://dx.doi.org/10.1016/j.enconman.2013.11.017

María Herrando, Christos N. Markides. Hybrid PV and solar-thermal systems for domestic heat and power provision in the UK: Techno-economic considerations. Applied Energy 161 (2016) 512-532.http://dx.doi.org/10.1016/j.apenergy.2015.09.025

P.K. Sen et al. Linear Fresnel mirror concentrator with tracking. Procedia Engineering 56 ( 2013 ) 613 - 618. doi: 10.1016/j.proeng.2013.03.167

Kelly, N. Solar energy conversion0 Resources and policy. University of Strathclyde 2010.

Shafiqur Rehman et al. A Combined Optical, Thermal and Electrical Performance Study of a V-Trough PV SystemExperimental and Analytical Investigations. Energies 2015, 8, 2803-2827.doi:10.3390/en8042803

M. ArifHasan, K. Sumathy. Photovoltaic thermal module concepts and their performance analysis: A review. Renewable and Sustainable Energy Reviews · September 2010.DOI: 10.1016/j.rser.2010.03.011

A. A. Ghoneim and A. M. Mohammedein. Experimental and Numerical Investigation of Combined Photovoltaic-Thermal Solar System in Hot Climate. British Journal of Applied Science \& Technology 16(3): 1-15, 2016.DOI: 10.9734/BJAST/2016/26151 